\title{
Processo de Trabalho e Eficiência Produtiva: Smith, Marx, Taylor e Lênin
}

\author{
- Benedito Rodrigues de Moraes Neto*
}

\begin{abstract}
RESUMO
A partir de reflexão sobre uma hipotética transição do capitalismo em sua natureza manufatureira ao socialismo, procura-se deixar marcada a razão pela qual, seguindo a proposta de Marx, essa transição exige que a produção se realize sob a égide da maquinaria. Consegue-se, como parte dessa reflexão, identificar, para o caso da manufatura, um trade-off entre eficiência produtiva e humanização das atividades de trabalho. Procura-se esclarecer que, dada a natureza do taylorismo-fordismo como "reinvenção da manufatura", o exercício de início especulativo passa a ter sentido histórico. Busca-se argumentar que a ampla assimilação do taylorismo-fordismo pela experiência de implantação do socialismo na União Soviética a aprisionou ao mencionado trade-off, fazendo com que a primeira experiência de superação do capitalismo se impregnasse perversamente da mediocridade imanente ao taylorismo-fordismo. Finalmente, são feitos rápidos comentários acerca dos desdobramentos da recente automação de base microeletrônica sobre a natureza de um projeto socialista.
\end{abstract}

\section{Palavras-Chave}

processo de trabalho, manufatura, eficiência produtiva, socialismo, taylorismo-fordismo, maquinaria

\begin{abstract}
From an analysis of a hypothetical transition from manufacture capitalism to socialism, we intend to stress the reason why, according to Marx's proposition, it is demanded that this transition takes place under machinery's domain. In the case of manufacture it is possible to identify a trade-off between the productive efficiency and the humanization of the labor activities. We then intend to clarify that the initially hypothetical speculation acquires a historic sense in as much as taylorism-fordism 's nature can be understood as a "reinvention of the manufacturing system". We shall then argue that the wide assimilation of taylorismfordism in the Soviet Union's experience of socialism implementation imprisoned it within the mentioned trade-off, which caused the first experience of capitalism's surmount to be perversely impregnated with the immanent mediocrity of taylorism-fordism. Finally, we shall comment briefly on the developments that the recent automation of microelectronic base might take in a socialist project.
\end{abstract}

KEYWORDS

labor process, manufacturing system, socialism, Taylorism-Fordism, machinery

\section{JEL CLASSIFICATION}

$B / 2, B / 4, L 23, P 30$

* Departamento de Economia - UNESP/Araraquara. Endereço para contato: Av. Caetano Mirabelli, I20 - São Carlos SP. E-mail: brmneto@gmail.com.

(Recebido em novembro de 2007. Aceito para publicação em julho de 2008). 


\section{INTRODUÇÃO}

Este texto nasceu de um exercício proposto para efeito pedagógico, qual seja, uma reflexão sobre os desdobramentos de uma transição direta da manufatura para o socialismo. $\mathrm{O}$ estudo das limitações postas pela forma manufatureira para o estabelecimento de uma formação social superior permitiria identificar a necessidade da maquinaria para a transcendência do capitalismo, o que nos levaria na direção de Marx. Numa primeira aproximação, este exercício, ainda que interessante, possuiria caráter exclusivamente hipotético, pois a forma manufatureira foi superada historicamente pela maquinaria, e a primeira tentativa de superação do capitalismo ocorreu, evidentemente, após essa superação. Todavia, as surpresas pregadas pelo século 20 no que se refere aos processos de trabalho irão permitir que o exercício proposto passe a tratar de aspectos históricos de grande importância. Por mais paradoxal que possa parecer, o século 20 permitirá esclarecer definitivamente a necessidade da máquina para a superação do capitalismo.

\section{AS LIMITAÇÕES DA MANUFATURA E O PROJETO SOCIALISTA}

O ponto de partida para a reflexão sobre os desdobramentos de uma eventual transição direta manufatura-socialismo vem a ser aquilo que pode ser denominado angústia smithiana, "consistente na inexorável vinculação estabelecida por Adam Smith entre eficiência produtiva e desumanização das atividades de trabalbo".. (MORAES NETO, 2004, p. 8), também conhecido como dilema smithiano (WEISS, 1976, p.106; PALMA, 1971, p. 15) Para Smith, se por um lado a elevação da eficiência produtiva, obtida exclusivamente pela via de incremento da divisão do trabalho (aqui divisão manufatureira do trabalho), possui um desdobramento extremamente positivo em função do incremento da riqueza material, por outro seus efeitos sobre a natureza das atividades de trabalho seriam extremamente perversos, como se depreende da conhecida frase enfática:

Com o avanço da divisão do trabalbo, a ocupação da maior parte daqueles que vivem do trabalho, isto é, da maioria da população, acaba restringindo-se a algumas operaçôes extremamente simples, muitas vezes a uma ou duas. Ora, a compreensão da maior parte das pessoas é formada pelas suas ocupaçôes normais. O homem que gasta toda sua vida executando algumas operações simples, cujos efeitos também são, talvez, sempre os mesmos ou mais ou menos os mesmos, não tem nenhuma oportunidade para exercitar sua compreensão ou para exercer seu espirito inventivo no sentido de encontrar meios para eliminar dificul- 
dades que nunca ocorrem. Ele perde naturalmente o bábito de fazer isso, tornando-se geralmente tão embotado e ignorante quanto o possa ser uma criatura bumana.... Este tipo de vida corrompe até mesmo sua atividade corporal, tornando-o incapaz de utilizar sua força fisica com vigor e perseverança em alguma ocupação para a qual foi criado. Assim, a habilidade que ele adquiriu em sua ocupação específica parece ter sido adquirida às custas de suas virtudes intelectuais, sociais e marciais. Ora, em toda sociedade evoluida e civilizada, este é o estado em que inevitavelmente caem os trabalbadores pobres - isto é, a grande massa da população...( SMITH, 1983, p. 213-214 ).

Vale lembrar um elemento fundamental para o esclarecimento da posição de Adam Smith, qual seja, a noção de que a forma manufatureira seria a mais avançada possível. Em função disso, e como não se colocaria para ele uma regressão histórica (WEISS, 1976), então não haveria como fugir do "mal necessário".

Lembremos que aquilo que estamos creditando a Smith, por influência de Ferguson, é assumido integralmente por Marx, que observa com clareza a razão maior da "angústia smithiana": o fato de que a forma manufatureira está inteiramente lastreada no ser humano como instrumento de produção.

Da natureza do trabalho sob a manufatura é possível, portanto, extrair um inexorável trade-off entre produtividade do trabalho e humanização das atividades de trabalho (implícito na formulação da angristia smithiana): caso se caminhe na direção da elevação da eficiência produtiva, então se terá que suportar o mal necessário, qual seja, a crescente desumanização do trabalho. Caso se opte por fornecer ao trabalho humano um grau mais elevado de humanização, ou seja, de apropriação subjetiva do trabalho pelos trabalhadores, de maior qualificação por parte do trabalhador, de maior conteúdo do trabalho, então se terá que sacrificar eficiência produtiva, caminhando-se na direção de um trabalho cada vez mais impregnado de caráter artesanal.

Vejamos agora quais seriam os desdobramentos de um processo de trabalho tão limitado quanto o manufatureiro para a implantação de relações de produção de natureza socialista. O ponto de partida para essa reflexão está, a nosso juízo, determinado desde logo pelo desafio da produção em massa, ou seja, da obtenção de elevados volumes de produção e de elevada eficiência produtiva, com vistas à satisfação das necessidades materiais de toda uma grande população. Pensando no sugerido tradeoff, não se imaginaria um caminho para o socialismo trocando produtividade por humanização de corte artesanal, dados os óbvios efeitos deletérios dessa opção em termos da satisfação das imensas necessidades materiais da sociedade. Caminhar-seia, portanto, e de forma inexorável, na direção da desumanização das atividades de 
trabalho, e a sociedade socialista teria então que conviver com esse mal necessário. Tratemos um pouco mais de perto desse ponto. Trata-se, como já observamos, de incrementar a eficiência produtiva através de utilização mais produtiva do instrumento de produção por excelência da manufatura, o trabalho vivo. Todavia, como notou Marx de forma feliz, "o homem é um instrumento muito imperfeito de produção quando se trata de conseguir movimentos uniformes e contínuos" (MARX, 1973, p. 306) Seria necessário, então, buscar alargar os limites inerentes àquilo que Marx chama de "barreira orgânica" tipicamente colocada pela forma manufatureira à expansão da produtividade do trabalho. Charles Babbage é extremamente claro ao observar os desafios postos por essa forma de expansão da eficiência produtiva:

A fadiga produzida nos misculos do corpo humano não depende completamente da força efetivamente empregada em cada esforço, mas parcialmente da frequiência através da qual ela é exercida. O esforço necessário para realizar cada operação consiste de duas partes: uma delas é o gasto de força que é necessário para guiar a ferramenta ou instrumento; $e$ a outra é o esforço requerido para a movimentação de algum membro do animal que produz a ação. Ao pregar um prego num pedaço de madeira, uma delas é erguer o martelo e impelir sua cabeça contra o prego; a outra é levantar o próprio braço, e movimentá-lo no sentido de usar o martelo. Se o peso do martelo é considerável, a primeira parte irá causar a maior porção do esforço. Se o martelo é leve, o esforço de levantar o braço irá produzir a maior parte da fadiga. Acontece portanto que aquelas operações que requerem uma força muito insignificante, se freqüentemente repetidas, irão cansar de modo mais efetivo do que o mais laborioso trabalho. Existe também um gran de rapidez além do qual não se pode forçar a ação dos músculos. (...) A proporção entre a velocidade através da qual homens ou animais se movem, e os pesos que carregam, é uma matéria de importância considerável, principalmente em assuntos militares. É também de grande importância para a gestão do trabalho fazer o ajuste entre o peso daquela parte do corpo do animal que se movimenta, o peso da ferramenta, e a freqüência de repetição desses esforços, de modo a produzir o melhor efeito. (...) Sempre que o trabalho é leve, torna-se necessário, de modo a economizar tempo, incrementar a velocidade. (BABBAGE, 1971, p. 30-32).

Em suma, é necessário, para efeito da conquista de incrementos na produtividade do trabalho, aperfeiçoar o conhecimento e a aplicação do ser humano como instrumento de produção, permitindo que o mesmo, de forma sempre aperfeiçoada, trabalhe com a "regularidade de uma peça de maquinaria" (MARX, 1973, p. 284). A questão que se coloca, portanto, para efeito de nosso exercício, é a de como conseguir esse 
efeito nos marcos de uma sociedade socialista, e analisar seus desdobramentos. Uma alternativa seria apelar para a emulação socialista, ou seja, para a apropriação subjetiva por parte dos trabalhadores da necessidade e da importância de trabalharem com a «regularidade de uma peça de maquinaria», desempenhando com firme disposição as tarefas parciais, repetitivas, de ciclo extremamente curto, a eles designadas pela expansão sempre buscada na divisão parcelar do trabalho. Essa alternativa implicaria, é óbvio, um socialismo hipervalorizador do trabalho manual, magnificador da condição operária imposta inexoravelmente pela natureza dos processos de trabalho eficientes. Tratar-se-ia de um projeto socialista prisioneiro da anguistia smithiana, de natureza bastante medíocre, posto que assentado em medíocres forças produtivas. Não é difícil esclarecer essa afirmação: imaginemos um mundo smithiano, no qual a forma mais avançada possível das forças produtivas seja encontrada na manufatura e sua divisão parcelar do trabalho. Essa eternização da manufatura seria, em nosso exercício, carregada para o interior do socialismo, num radical "fim da História" das forças produtivas. Ter-se-ia então que eternizar a emulação socialista para garantir a conquista de elevada eficiência produtiva, coisa que, ademais de impossível, seria absolutamente indesejável, pois a sociedade jamais chegaria a uma efetiva condição de superioridade $v i s$ - $\grave{a}$-vis o capitalismo. O que se conseguiria, na melhor das hipóteses, seria um socialismo magnificador da condição operária. E essa seria a melhor das hipóteses, pois uma outra não pode ser esquecida: a conquista de elevada produtividade do trabalho de forma amplamente autoritária. Nos dois casos, nosso «socialismo manufatureiro» apresentaria todas as condições para ser caracterizado como grosseiro, para usar expressão de Marx nos Manuscritos de 44. O fato de que Marx observava claramente a impossibilidade de uma hipotética transição direta manufatura-socialismo - marcando assim a necessidade da maquinaria - nos é revelado claramente pela forma irônica com que tratou a proposta de Proudhon de rodízio de tarefas entre trabalhadores parciais com vistas a amenizar os efeitos deletérios da divisão do trabalho. (MARX, 1976, p. 114).

Qual a razão fundamental pela qual Marx despreza a possibilidade de transitar do capitalismo para o socialismo nos marcos de uma base técnica manufatureira? Pelo fato de que este seria um socialismo reforçador do trabalho manual sem conteúdo, antítese da visão extremamente ambiciosa de Marx de um socialismo que teria como característica fundamental a de caminhar no sentido da «abolição do trabalho»:

Apenas nesta fase [após a revolução] a auto-atividade coincide com a vida material, o que corresponde à transformação dos individuos em individuos totais e ao despojamento de todo seu caráter natural. A transformação do trabalho em auto-atividade corresponde à transformação do limitado intercâmbio anterior em intercâmbio entre individuos enquanto tais. Com a apropriação das forças produtivas totais pelos indi- 
viduos unidos, termina a propriedade privada. (MARX; ENGELS, 1991, p. 106-107).

Em todas as revoluçôes anteriores o modo de atividade permanecia intacto, e tratava-se apenas de conseguir uma outra forma de distribuição dessa atividade, uma nova distribuição do trabalho entre outras pessoas, enquanto que a revolução comunista é dirigida contra o modo anterior de atividade, suprime o trabalho e supera a dominação de todas as classes ao superar as próprias classes, porque esta revolução é feita pela classe que não é mais reconbecida como tal, e que já é em si mesma a expressão da dissolução de todas as classes, de todas as nacionalidades, etc., no interior da sociedade atual. (ibidem, p. 108).

Para Marx, portanto, a abolição da sociedade de classes exige a transcendência do trabalho alienado, ou seja, a abolição do trabalho. À primeira vista, um «socialismomanufatureiro» impregnado de emulação socialista estaria superando a alienação do trabalho. Todavia, tratar-se-ia de visão superficial, pois a eternização do homem como instrumento fundamental de produção trataria de repor historicamente a sociedade de classes. Afinal, nos ensina Marx, "uma análise do conceito de trabalbo estranbado mostra que, muito embora a propriedade privada pareça ser a razão, a causa do trabalbo alienado, ela é, ao invés disso, sua conseqüência.” (MARX, 1974, p. 116) Pode-se, então, entender a razão mais profunda pela qual, para Marx, o capitalismo não seria apenas mais uma, mas a última sociedade de classes: por ter superado historicamente a dependência do ser humano como instrumento de produção, ou seja, por ter feito surgir a produção sob a égide da maquinaria.

\section{A NECESSIDADE DA MÁQUINA: A SUPERAÇÃO DO TRADE-OFF IM- PLÍCITO NA «ANGÚSTIA SMITHIANA»}

Marquemos a necessidade, em Marx, da produção inteiramente dominada pela maquinaria para que se possa transitar do capitalismo para o socialismo:

Trabalharás com o suor de teu rosto!, foi a maldição que Jeová lançou a Adão, e é desta maneira, como maldição, que Adam Smith concebe o trabalho. O 'repouso' aparece como o estado adequado, como idêntico à 'liberdade' e à 'fortuna'. Parece estar muito longe de seu pensamento que o individuo, 'em seu estado normal de saúde, vigor, atividade, habilidade e destreza' tenba também a necessidade de sua porção normal de trabalho e da supressão do repouso. (...) Tem razão, sem dívida, Adam Smith, na medida em que as formas históricas de 
trabalho - como trabalho escravo, servil, assalariado - sempre se apresentaram como trabalho forçado, imposto exteriormente, frente ao qual o não-trabalho aparece como 'liberdade e fortuna'. Isto é duplamente verdadeiro: é verdadeiro com velação a este trabalbo antitético ['quer dizer, condicionado por uma antitese de classe' (ROSDOLSKY, 1985, p. 474)], e, em conexão com ele, ao trabalho para o qual ainda não se criaram as condiçôes subjetivas e objetivas para que se torne trabalho atraente, auto-realização do individuo, o que de modo algum significa que seja mera diversão, mero entretenimento, como concebia Fourier. Precisamente, os trabalhos realmente livres, como por exemplo a composição musical, são ao mesmo tempo terrivelmente sérios e exigem o mais intenso dos esforços. O trabalho da produção material só pode adquirir esse caráter (de trabalho realmente livre, emancipado ) : 1) Se o seu conteuido se tornar diretamente social; 2) Se se revestir de um caráter cientifico e surgir diretamente como tempo de trabalho geral. Por outras palavras se deixar de ser o esforço do homem, simples força de trabalho natural no estado bruto tendo sofrido um determinado treinamento, para se tornar a atividade do sujeito que regula todas as forças da natureza no seio do processo de produção. (MARX, 1978, p. 119-120).

Como afirmamos anteriormente, toda a reflexão realizada até aqui parece ter um caráter puramente especulativo, na medida em que Marx realizava sua análise a partir do revolucionamento causado pela introdução da maquinaria. Na medida em que esta teria superado radicalmente a forma manufatureira, a ideia de uma transição da manufatura para o socialismo não teria qualquer sentido histórico. Todavia, como também já afirmamos, as surpresas pregadas pelo século XX vão permitir que o exercício feito até aqui possa conter importantes elementos histórico-concretos. A responsabilidade integral por isso deve ser debitada à emergência histórica do taylorismo-fordismo, pelas razões que se seguem.

\section{A NATUREZA CONCEITUAL DO TAYLORISMO-FORDISMO}

Demarquemos, neste momento, a natureza conceitual do taylorismo-fordismo:

... taylorismo caracteriza-se como uma forma avançada de controle do capital (com o objetivo de elevar a produtividade do trabalho) sobre processos de trabalbo nos quais o capital dependia da habilidade do trabalhador... De que forma? Através do controle de todos os tempos e movimentos do trabalhador; ou seja, do controle de todos os passos do 
trabalho vivo. Estamos bastante distantes da forma descrita por Marx do ajustamento da base técnica às determinações do capital: num momento mais avançado do desenvolvimento do capitalismo, à questão historicamente recolocada de sua dependência frente ao trabalho vivo, o capital reage de uma forma diferente: ao invés de subordinar o trabalho vivo através do trabalbo morto, pelo lado dos elementos objetivos do processo de trabalho, o capital lança-se para dominar o elemento subjetivo em si mesmo. Esta 'façanba' do capital significa, em uma palavra, a busca da transformação do homem em máquina. (MORAES NETO, 1989, p. 34).

O fordismo caracteriza o que poderiamos chamar de socialização da proposta de Taylor, pois, enquanto este procurava administrar a forma de execução de cada trabalho individual, o fordismo realiza isso de forma coletiva, pela via da esteira. (ibidem, p. 36-37).

Pode-se aplicar sem restrições para a linha de montagem a colocação feita por Marx para a manufatura: 'A maquinaria especifica do periodo da manufatura é, desde logo, o próprio trabalhador coletivo, produto da combinação de muitos trabalhadores parciais'. (ibidem, p. 51).

Após essas considerações, chegamos à seguinte conclusão: o fordismo, a linha de montagem, é um desenvolvimento da manufatura, e não da maquinaria. A linha de montagem leva ao limite as possibilidades de aumento de produtividade pela via da manufatura, do trabalho parcelar. (ibidem, p. 33).

O desdobramento evidente dessa concepção teórica é que o trade-off implícito na "angústia smithiana” irá assombrar o século 20, na medida em que vai repor todas as limitações imanentes à forma manufatureira. Tentaremos a seguir ilustrar essa assertiva dentro do contexto da busca de superação do capitalismo.

\section{SOCIALISMO E EFICIÊNCIA PRODUTIVA: O CASO DA UNIÃO SOVIÉTICA}

Sendo o taylorismo-fordismo uma "reinvenção da manufatura", a conhecida e polêmica incorporação ampla do taylorismo-fordismo pela experiência socialista encetada na União Soviética a levaria a aprisionar-se ao trade-off implícito na «angústia smithiana»e, consequentemente, a trazer para a História os limites anteriormente apontados para a transição direta manufatura-socialismo. 
É bastante conhecida a diretriz lançada por Lênin logo após 1917, em relação à aplicação dos princípios tayloristas pela nascente experiência socialista:

Em comparação com o pessoal das nações avançadas, o russo é um mau trabalbador. E não podia ser de outro modo sob o regime tzarista, e em virtude da persistência dos resquicios do sistema feudal. Aprender a trabalhar, eis a tarefa que o poder soviético deve colocar ao povo em toda sua extensão. A última palavra do capitalismo neste terreno - o sistema Taylor - , do mesmo modo que todos os avanços do capitalismo, reúne em si toda a ferocidade refinada da exploração burguesa e uma série das maiores conquistas cientificas referentes ao estudo dos movimentos mecânicos durante o trabalho, a supressão dos movimentos supérfluos e torpes, a elaboração de métodos de trabalho mais racionais, a implantação de melhores sistemas de registro e de controle, etc. A República Soviética deve adotar, a qualquer custo, as conquistas mais valiosas da ciência e da técnica neste domínio. A possibilidade de se construir o socialismo depende precisamente do êxito que logremos, ao combinar o poder soviético e a organização soviética da direção com as últimas conquistas do capitalismo. Devemos organizar na Rússia o estudo e o ensino do sistema Taylor, experimentá-lo e adaptá-lo sistematicamente aos nossos próprios fins. (LÊNIN, 1988b, p. 164).

Como já deixa claro a frase acima, e se trata de fato bastante conhecido, há uma ambivalência na posição de Lênin, pois admite-se o taylorismo como possuidor de caráter de "arma antiproletária, de 'crueldade refinada da exploração burguesa' (...), mas também se enfatiza com grande vigor seu aspecto de avanço técnico-cientifico" (FINZI, 1986, p.140) Existe já nessa ambivalência uma pista importante, seguida por vários estudiosos, para perscrutar o que haveria de conceitual em Lênin sobre o taylorismo. O início de seu percurso sobre o tema situa-se no lado contundentemente crítico: em artigo de 1913 afirma tratar-se o taylorismo de um "método científico de extorsão de suor", e que,

Como resultado desse método, três vezes mais trabalho é extraído do trabalhador nas mesmas nove a dez horas de trabalho diário; toda a força do trabalbador é incitada de maneira inclemente, cada pedaço de nervos e músculos é exaurido do trabalhador escravo a um ritmo três pezes maior (...) (LÊNIN, 1972, p. 594-595, apud TRAUB, 1978, p. 82).

Todavia, em artigo de março de 1914, o lado crítico permanece, mas o lado positivo, tendo em conta o projeto socialista, começa a surgir [este artigo constitui, para 
Devinatz, a "ponte" que nos permite caminhar do ponto inicial, em 1913, para o tratamento pós-revolucionário (DEVINATZ, 2003, p. 515)]:

O sistema Taylor - sem que seus autores o saibam e contra sua vontade - prepara o tempo em que o proletariado tomará nas mãos toda a produção social (...), (à medida que) as comissóes operárias, com a ajuda dos sindicatos, saberão aplicar estes princípios de distribuição racional do trabalho social, quando ele estiver emancipado de sua submissão ao capital. (LÊNIN, 1914, apud FINZI, 1986, p. 139).

Observa-se que "Tão cedo como 1914, Lênin argumentou que o taylorismo era ao mesmo tempo uma forma de extrair a última gota de suor do trabalbador e de conseguir 'um enorme ganbo em termos de produtividade do trabalbo'” (SOCHOR, 1981, p. 248).

Com o objetivo de estudar a ligação de Lênin com o taylorismo, perseguindo a pista já aberta pelo artigo de 1914, os estudiosos têm dado grande ênfase ao tratamento dado a esse tema no material preparatório para $O$ Imperialismo, cuja confecção se atribui aos anos 1915-1916 (FINZI, 1986, p. 140-142; LINHART, 1977, p. 97-98) O caminho aí perseguido por Lênin, que vai permitir entender sua posição pós-17, deve-se inteiramente ao fato de que, para ele, o taylorismo ilustrava à perfeição o estágio mais avançado das forças produtivas alcançado pelo capitalismo:

O famoso sistema Taylor, muito difundido na América do Norte, é célebre porque constitui a última palavra da mais desenfreada exploração capitalista. É natural, então, que esse sistema tenha provocado tanto ódio e indignação entre as massas operárias. Mas ao mesmo tempo, não se deve esquecer um só instante que o sistema Taylor implica num enorme progresso da ciência, que analisa sistematicamente o processo de produção e abre caminho para um grande aumento da produtividade do trabalho humano. As investigaçôes cientificas iniciadas na América do Norte à raiz da implantação do sistema Taylor, em particular o estudo dos movimentos, como dizem os norte-americanos, deram como resultado um rico material que permitiu ensinar à população trabaLhadora métodos muitíssimo mais elevados de trabalho em geral e de organização do trabalho em particular. (LÊNIN, 1988a, p. 120).

Sobre esse ponto, são felizes as observações abaixo:

(...) para Lênin, o taylorismo estava vinculado com o avanço geral do capitalismo, o qual era positivamente interpretado na medida em que pavimentava o caminho para o socialismo. A questão essencial para 
Lênin tornou-se politica: quem iria controlar e usar o taylorismo. (SOCHOR, 1981, p. 248).

Não há dívida de que, no taylorismo, Lênin vê um aspecto cientifico num sentido, por assim dizer, próprio e estrito: de progresso dos conhecimentos naturais, de maior penetração nos segredos da natureza, de avanço da capacidade humana de submeter a si o mundo natural. Dai sua constante ênfase na importância das conquistas tayloristas no estudo dos movimentos. (FINZI, 1986, p. 144).

Lênin efetua, portanto, uma equivocada aliança entre taylorismo e cientificização dos processos produtivos, entre taylorismo e produção à base de maquinaria. Esta aliança já existia no artigo crítico de 1913, no qual se afirma que o taylorismo "levava ao extremo a escravização da humanidade à máquina" e permitia observar que "avanços nas esferas da tecnologia e da ciência na sociedade capitalista são todavia avanços na arte de extorsão de suor” (LÊNIN, 1972, p.595, apud TRAUB, 1978, p.82) Também é muito significativa a visão de Lênin, no momento imediatamente pós-revolucionário, de que o taylorismo poderia "facilitar o processo de trabalho e oferecer algum alivio ao trabalbador através da transferência do penoso trabalbo físico para a máquina" (grifo nosso). (TRAUB, 1978, p.84) Sendo assim, o passo seguinte - o da proposta de aceitação, em alguns momentos até entusiasmada, do taylorismo pelo projeto socialista - passa a ser inteiramente justificado à luz de Marx. Como já enfatizamos, para Marx, a produção sob a égide da máquina, transformada em "aplicação tecnológica da ciência", é a grande contribuição histórica do modo de produção capitalista e a base produtiva sobre a qual se deve erigir uma sociedade que transcenda o capitalismo. Se o taylorismo se encaixa perfeitamente dentro dessa contribuição do capital, então sua assunção pelo socialismo é não só inexorável como benfazeja, pois assim se poderia eliminar seu lado negativo e preservar seu lado positivo. ${ }^{l} \mathrm{O}$ problema surge quando se considera o taylorismo (mais especificamente, o taylorismo-fordismo) como algo que não se encaixa de forma alguma dentro dessa positividade das forças produtivas capitalistas, caracterizando-se, isto sim, como uma forma imanentemente medíocre de organização produtiva, inteiramente prisioneira da tão milenar noção de que produzir é utilizar da mais eficiente forma possível o ser humano em sua

1 A ligação estreita entre Taylor e a ciência, na forma de "ciência do trabalho", e o papel da ciência em Marx são, para James Scoville, elemento fundamental da compreensão da aceitação do taylorismo por Lênin, a qual antecede, como já vimos, o momento pós-revolucionário e suas exigências de elevação da produtividade: "Nós precisamos focalizar nosso olhar na importância do conceito de 'ciência' na estrutura intelectual do marxismo. Marx realizou a análise cientifica do capitalismo; os marxistas desenvolveram as bases para o 'socialismo cientifico'. Quando 'a ciência do trabalho' apareceu, ela foi adotada sem rodeios como uma parte natural do esquema geral. Para colocar de forma alternativa, a gerência não-científica do trabalho seria não-marxista. A gerência cientifica, tão repreensível sob o capitalismo, não é abrupta e inconsistentemente aceitável para o socialismo, mas de fato uma característica necessária desse tipo de Estado" (SCOVILLE, 2001, p. 625). 
corporalidade como instrumento por excelência de produção. ${ }^{2}$ Caso este fosse o entendimento de Lênin sobre o taylorismo, então se teria uma base conceitual para justificar a afirmação de Devinatz de que "Lênin via o taylorismo apenas como uma medida temporária (...)” (DEVINATZ, 2003, p.514), à qual o autor não consegue dar sustentação, sendo obrigado a concluir sua argumentação dentro do terreno das possibilidades. ${ }^{3}$ Aliás, nada melhor para ilustrar o caráter imanentemente medíocre do taylorismo do que uma referência a comentários de Alexei Gastev, grande ideólogoprofessor-divulgador do sistema Taylor na Rússia Soviética na fase imediatamente pós-revolucionária. Vale lembrar que Gastev foi fundador e diretor do Instituto Central do Trabalho, instituição que contou com o crucial apoio de Lênin, e foi também o grande vencedor da forte polêmica sobre taylorismo que culminou na Segunda Conferência sobre Organização Científica do Trabalho, ocorrida em março de 1924. ${ }^{4}$ Vejamos então algumas colocações esclarecedoras de (e sobre) Gastev:

Na visão romântica de Gastev do fenômeno industrial, homens e máquinas se fundiam: as máquinas eram vistas como extensões do corpo bumano, ao mesmo tempo em que as pessoas assumiam a velocidade e a eficiência de suas criações, adquirindo 'nervos e músculos de aço'. (BAILES, 1977, p. 374).

Precisamos agora dirigir nossos esforços, não na direção de uma prolixa ciência geral, mas sim na direção da criação, o mais rápido possível, de um determinado número de máquinas de trabalbo vivo qualificadas, excepcionalmente disciplinadas, prontamente disponíveis para serem postas em circulação geral. (GASTEV, 1924, apud BAILES, 1977, p. 387, grifo nosso).

Gastev afirmava que os próprios trabalhadores se tornariam crescentemente mecanizados, como dentes de engrenagem em uma enorme máquina. (BAILES, 1977, p. 378)

A organização do Instituto Central do Trabalho numa série de laboratórios de bio-mecânica, fisiologia e psico-fisiologia se ajustava à ênfase de Gastev no fator humano como a dimensão desconbecida na organização cientifica do trabalbo (...) (Gastev estava) preocupado em desenvolver

2 Esta é uma crítica à incorporação de Taylor por Lênin bastante diferente da formulada pelos "comunistas de esquerda" no período pós-revolucionário, que se reproduziu bem mais recentemente na chamada "crítica às forças produtivas capitalistas", que ainda possui importante presença. (DEVINATZ, 2003) Para uma "crítica à crítica das forças produtivas capitalistas", ver MORAES NETO (1989).

3 "Se Lênin apoiaria a implementação da gerência científica sob o socialismo é uma questão em aberto; é bastante possível que Lênin não teria advogado o uso do taylorismo sob o socialismo.” (DEVINATZ, 2003, p. 519).

4 Para Wren e Bedeian, o apoio de Lênin foi determinante para essa vitória: "Em virtude do fato de que Lênin, que presidiu a conferência, era pró-Taylor, o Instituto Central do Trabalho de Gastev recebeu a chancela da conferência.” (2004, p. 291). 
uma 'ciência exata da organização de uma planta recheada de gente'. $O$ homem era o fator critico a ser estudado e a ser transformado pela aplicação dos principios da Organização Cientifica do Trabalho. Muito embora a 'máquina bumana' fosse capaz de produzir milagres, não mais do que um décimo dessa máquina viva era conbecido, lamentava Gastev. Por essa razão, o Instituto Central do Trabalho se dedicava a examinar 'os mecanismos separados (da máquina humana) em operação'. (SOCHOR, 1981, p. 254-255, grifos nossos)

De acordo com um visitante do Instituto Central do Trabalho, 'qualquer um que cruze a porta da frente desse instituto como um ser bumano normal, sairá pela porta de trás, depois de ter passado por incontáveis laboratórios, como uma perfeita máquina de trabalbo'. (ibidem, p. 264, grifo nosso).

Não há dúvida de que Gastev entendeu perfeitamente a essência do taylorismo, qual seja, a tentativa de transformar o homem em máquina, e a explicitou várias vezes de forma crua: "Muitos acham repugnante que nós queiramos tratar o ser humano como um parafuso, uma porca, uma máquina. Mas nós precisamos fazer isso tão tranqüilamente como aceitamos o crescimento das árvores ou a expansão da rede ferroviária."(apud TRAUB, 1978, p. 88) Em poema escrito para a leitura do proletariado russo ao final dos anos 20, afirmou: "Eu desenvolvo braços e ombros de aço - eu me fundo com a forma do aço." (apud TRAUB, 1978, p. 87) Todavia, a despeito do esforço das colocações e da prática de Gastev para demonstrar (de forma involuntária, é claro) o caráter extremamente atrasado e medíocre do taylorismo relativamente ao conceito de máquina exposto por Marx, potencialmente libertador do homem do trabalho, ele não teve sucesso: a despeito da polêmica em torno do tema, o taylorismo foi assumido pelos dirigentes do projeto socialista na União Soviética como uma contribuição do capitalismo para o avanço das forças produtivas, cuja incorporação pela experiência socialista seria indispensável e positiva.

A esse ponto de partida conceitual sobre taylorismo e forças produtivas deve-se acrescentar um aspecto histórico específico da experiência soviética, qual seja, a necessidade extrema de elevação rápida da produtividade do trabalho. Essa urgência, que adquiriu tons dramáticos em função de vicissitudes do período pós-revolucionário, irá reforçar a necessidade da incorporação rápida do taylorismo-fordismo, e moldar o formato dessa incorporação. Este ponto já pode ser visualizado em frase de Lênin já em 1918, a respeito de decreto proposto sobre disciplina no trabalho:

No decreto, nós precisamos definitivamente nos reportar à introdução do Sistema Taylor; em outras palavras, do uso de todos os métodos cientí- 
ficos de trabalho, com seus sistemas avançados. Sem isso, será impossivel elevar a produtividade, coisa que, se não conseguirmos, não nos conduziremos ao socialismo. (LÊNIN, 1918, apud BAILES, 1977, p. 376).

Para nós, o entendimento do taylorismo por Lênin e sua assunção para elevar substancial e rapidamente a produtividade do trabalho irá jogar a experiência socialista nascente na armadilha do trade-off implícito na "angústia smithiana". O taylorismofordismo irá trazer para o concreto histórico aquilo que vimos hipoteticamente na transição direta manufatura-socialismo. Ainda que não esclareça suas determinações, Kendall Bailes explicita com clareza esse trade-off:

As resoluçôes da Conferência de março de 1924 moldaram as diretrizes básicas para o esforço soviético em termos de racionalização do trabalho bumano durante os anos seguintes de rápida industrialização. (...) $A$ Conferência atenuou a tensão que normalmente existe, em qualquer economia, entre incrementar a eficiência humana, por um lado, e, por outro, proteger a saúde e os interesses monetários do trabalhador individual. (BAILES, 1977, p. 392).

Interessante é observar que, num primeiro momento pós-revolucionário, Lênin pareceu não se esquecer dos aspectos negativos do taylorismo que enfatizara nos artigos dos anos 1913 e $1914 .{ }^{5}$ Na primeira versão de As tarefas imediatas ... existem considerações que embasam essa afirmação, as quais foram eliminadas da versão definitiva do texto:

O negativo no sistema Taylor é que foi aplicado na escravidão capitalista e serviu de meio para extrair dos operários uma quantidade dupla ou tripla de trabalho com o mesmo salário, desprezando qualquer consideração acerca da capacidade dos operários assalariados para render, sem prejuizo para seu organismo, essa quantidade dupla ou tripla de trabalho em igual número de horas. A República Socialista Soviética enfrenta uma tarefa que pode ser formulada em poucas palavras, do seguinte modo: devemos implantar em toda a Rússia o sistema Taylor e a elevação cientifica da produtividade do trabalho conseguida pelos norte-americanos, conjugando este sistema com a redução do tempo de trabalho, com o emprego de novos métodos de produção e de organização do trabalho, sem prejudicar por minimo que seja a força de trabalho da

5 Este ponto é realçado por Rainer Traub: "O taylorismo deveria ser sistematicamente testado e avaliado. Lênin ainda rejeitava fortemente o chamado lado negativo do taylorismo: a intensificação do processo de trabatho às custas da sauide e do bem-estar do trabalhador. Ele acreditava, todavia, que o seu lado 'positivo', a saber, crescente produtividade, acompanhada de uma organização do trabalho aperfeiçoada, poderia ser extraido do uso capitalista do taylorismo e empregado de uma forma socialista." (TRAUB, 1978, p. 84). 
população trabalbadora. Ao contrário, a aplicação do sistema Taylor, corretamente dirigida pelos próprios trabalbadores se estes são bastante conscientes, será a melhor garantia para que no futuro se possa reduzir enormemente a jornada obrigatória de toda a população trabalbadora, será a melhor garantia para que num periodo bastante breve realizemos o objetivo que pode-se expressar aproximadamente da seguinte maneira: seis horas de trabalho fisico para cada cidadão adulto e quatro horas de trabalbo para a administração do Estado. (LÊNIN, 1988a, p. 120-121).

Como afirma Linhart, "o sonho das 'seis horas-quatro horas' não sobreviveu à urgência da situação. O texto final de As tarefas imediatas...recuou bastante.” (LINHART, 1977, p. 123). Ou seja, as circunstâncias históricas foram dissipando, da ambivalência leninista sobre Taylor, o lado negativo, fazendo com que o lado positivo preponderasse. Ficavam assim postas todas as condições para que a experiência socialista nascente fosse capturada pela armadilha do trade-off eficiência produtiva versus humanização do trabalho. Esse movimento leva a que a elevada produtividade do trabalho possa ser alcançada, como já mencionamos na hipotética transição direta manufaturasocialismo, através de duas alternativas de interferência sobre o rendimento do homem enquanto instrumento de produção: a emulação socialista-revolucionária ou o mais aberto autoritarismo. Segundo Linhart, logo após a superação da proposta de redução da jornada de trabalho pela necessidade de elevar rapidamente a produção e a produtividade, Lênin foi imensamente atraído pela emulação revolucionária como arma fundamental para a incorporação do taylorismo, fato que pode ser visualizado pela forma entusiasta com que acolheu a experiência dos «sábados comunistas», nos quais operários deslocados para tarefas ligadas às mais prementes necessidades postas pela Guerra Civil retomavam seu contato com o trabalho produtivo (LINHART, 1977, p. 158). Linhart também nos lembra que as vicissitudes da Guerra Civil empurraram a maior fatia do proletariado urbano, envolvido com as lutas revolucionárias, para as tarefas ligadas mais imediatamente ao esforço de guerra, causando sua substituição por um contingente em nada comprometido com o esforço revolucionário. Este fenômeno - que levou Lênin em 1921 a explicitar a noção do "desaparecimento do proletariado" - ocasionou a necessidade da troca da "emulação revolucionária" pelo aberto autoritarismo como forma de conquistar um padrão mínimo de produtividade do trabalho. Mantemo-nos, portanto, dentro das opções postas pelo aprisionamento ao trade-off implícito na "angústia smithiana" para a conquista de elevada eficiência produtiva em um projeto socialista: emulação socialista-revolucionária ou autoritarismo. $\mathrm{O}$ interessante é marcar que a determinação última da opção tomada encontra-se em aspecto fundamental da forma fordista de organizar o processo de trabalho, exposta com felicidade por Gramsci quando afirma que "os novos métodos de trabalho (fordistas) são indissolúveis de um determinado 
modo de viver, de pensar e de sentir a vida." (GRAMSCI, 1978, p. 328) Em outras palavras, na medida em que o taylorismo-fordismo fundamenta-se no uso massivo de trabalho vivo imediato (como muito bem lembrou Gastev), então sua eficiência depende fundamentalmente do que se passa nas mentes desses instrumentos humanos de produção. No caso que nos interessa aqui, a experiência soviética, isso permitirá, como veremos a seguir, que a arma da "emulação revolucionária" volte a ocupar o centro do palco, com o advento do famigerado stakhanovismo em 1935, movimento que ajuda sobremaneira na caracterização do taylorismo-fordismo como imanentemente medíocre, não sendo portanto nada surpreendente a grande confluência entre o stakhanovismo e Gastev:

Em janeiro de 1936, Ordzhonikidze, Comissário da Indústria Pesada, incumbiu Gastev da preparação de quadros para o movimento stakbanovista. Em 1938, de acordo com uma recente estimativa soviética, aproximadamente um milhão de trabalbadores industriais haviam sido preparados pelos métodos e instrutores do Instituto de Gastev - um indicador da dimensão que sua influência adquiriu naqueles anos. (BAILES, 1977, p. 393).

Sobre a importância adquirida pelo stakhanovismo na prática produtiva, e também sobre a ligação deste movimento com Gastev, consultemos também Wren e Bedeian:

Em julho de 1938, 29\% de todos os membros de sindicato na União Soviética tinham sido qualificados como Stakbanovistas. Em 1939, esse numero cresceu para $34 \%$ de todos os membros de sindicato (que compreendiam $80 \%$ da força de trabalho). (...) V.M.Molotov falou na primeira Conferência dos Stakhanovistas de Todos os Sindicatos, em 1936, e Joseph Stalin continuou a exaltá-los como o modelo soviético de trabalbadores. Os stakhanovistas traziam uma nova retórica de gestão, reforçando a altruismo do trabalho duro e da devoção ao Estado. (...) O que Alexei Stakbanov iniciou tornou-se uma norma nacional. G.K. Ordzhonikidze, Presidente do Conselho Supremo da Economia Nacional, colocou Gastev na função de treinar stakbanovistas. No Instituto de Gastev, quadros de trabalbadores seriam treinados para se tornarem 'rate-busters', e irem para as fábricas como um exemplo para os demais. (WREN; BEDEIAN, 2004, p. 294).

Para deixar marcada a grande influência do stakhanovismo, ou seja, da assunção do taylorismo-fordismo sob o manto da "emulação socialista" sobre toda a História posterior da experiência soviética, lembremos Stalin: 
Stalin disse na primeira conferência stakbanovista (Novembro de 1935): '(...) este movimento começou (...) quase espontaneamente, de baixo, sem que nenhuma pressão tenha sido exercida pela administração das nossas empresas. Mais, este movimento nasceu e desenvolveu-se, em certa medida, contra a vontade da administração das nossas empresas, e até mesmo numa luta contra ela." Stalin apresenta o movimento stakbanovista como uma espécie de revolução cultural, um salto em frente no sentido da supressão da diferença trabalho manual-trabalho intelectual: 'Não há dívida que só este avanço cultural e técnico da classe operária pode minar as bases da oposição entre o trabalho intelectual e o trabalho manual (...) O movimento stakhanovista (...) contém os primeiros germes (...) deste avanço cultural e técnico da classe operária do nosso pais.' (LINHART, 1977, p. 122).

É interessante notar que a vinculação entre stakhanovismo e taylorismo não é aceita por Wren e Bedeian, para quem "Com os 'shock-workers' e os stakhanovistas, os preceitos da gerência cientifica sobre estudos cuidadosos e análise dos métodos de trabalho e ferramentas apropriados foram violados." (WREN; BEDEIAN, 2004, p.294) Para esses autores, o taylorismo caracteriza-se por ser científico e objetivo, o que o afastaria de algo como o stakhanovismo, amplamente vinculado à emulação revolucionária:

O gráfico de Gantt era neutro ideologicamente, e constituiu a base para os planos quinquenais e o planejamento fabril. Em outras técnicas, os preceitos de Taylor foram violados. Onde ele propôs estabelecimento de padrões baseados no estudo e na análise, os 'shock-workers' e os stakhanovistas se tornaram os modelos soviéticos; e onde ele propôs cooperação, a disciplina se tornou mais rígida. (WREN; BEDEIAN, 2004, p. 297).

É essa uma visão do taylorismo como possuidor de natureza "científica e objetiva" (além de não autoritária, mas "cooperativa"), coisa impossível de ser alcançada, na medida em que ele mantém o ser humano como o instrumento de produção por excelência. (MORAES NETO, 1989) Também se encontra na literatura, a partir da mesma visão sobre a natureza do taylorismo, uma verdadeira oposição entre este movimento e o stakhanovismo: "Os métodos bárbaros do stakbanovismo e do trabalbo forçado eram incompativeis com qualquer forma de 'scientific management" (TRAUB, 1978, p. 92) Também em Bedeian e Phillips se observa, se não uma oposição, pelo menos uma diferença de fundo entre a scientific management e o stakhanovismo, não muito bem caracterizada; ela parece surgir quando são colocados os problemas de eficiência produtiva gerados pelos excessos do stakhanovismo: a gerência científica seria objetiva e racional, enquanto o stakhanovismo apresentaria uma considerável 
dose de irracionalismo. Se superarmos essa visão do taylorismo como algo impregnado de cientificidade, de objetividade, coisa que nos parece necessária, podemos então visualizar o stakhanovismo como uma forma histórica do taylorismo, um neotaylorismo, quando o projeto de utilização ao paroxismo do homem como instrumento de produção é internalizado pelo homem trabalhador pela via da "emulação revolucionária". Pode-se inclusive traçar uma analogia entre este neotaylorismo e o neotaylorismo-fordismo representado pelo ohnoísmo (ou toyotismo), no qual o capital mantém as atividades de trabalho desprovidas de conteúdo e conquista um elevado grau de envolvimento dos trabalhadores com a empresa e o trabalho. ${ }^{6}$

Não devemos nos esquecer, todavia, que, no caso de arrefecimento da "emulação socialista-revolucionária”, o autoritarismo sempre estaria à mão como alternativa para tentar obter eficiência produtiva. A História acabou mostrando, todavia, os estreitos limites colocados pela utilização, num prazo mais longo, dessas alternativas postas à disposição do socialismo de base taylorista-fordista. Em poucas palavras, o desvio mediocrizante representado pelo taylorismo-fordismo - e a dificuldade de compreendê-lo - acabou por impactar perversamente a primeira tentativa histórica de superação do regime capitalista, contribuindo fortemente para seu caráter e, acreditamos, para seu fracasso. Isto porque, quando a emulação revolucionária desaparece, e o autoritarismo se burocratiza, o sistema caminha inexoravelmente pela senda da ineficiência e do desalento.

\section{CONSIDERAÇÕES FINAIS}

Procuramos assentar até aqui o fato de que, sendo o taylorismo-fordismo uma reinvenção da manufatura, sua assimilação pela experiência de implantação do socialismo na União Soviética acabou por ilustrar concretamente os limites postos pela manufatura para a implantação de uma forma social progressiva em relação ao capitalismo. Ocorre que, no final do século 20, no capitalismo desenvolvido - e não no interior da experiência socialista ${ }^{7}$-, pela via do revolucionamento tecnológico proveniente da automação de base microeletrônica, a planta taylorista-fordista foi "explodida":

6 Sobre essa visualização do ohnoísmo (ou toyotismo) como um sistema de produção que mantém no fundamental as características do trabalho sob o taylorismo-fordismo - um neofordismo - , ver Wood (1991; 1993) e Moraes Neto (1998).

7 É bastante provável que uma correta visualização da natureza imanentemente medíocre do taylorismofordismo pudesse ter atuado positivamente no sentido de que sua superação se tivesse efetivado no interior da experiência socialista. Sua aceitação como forma de produção avançada (um "fim da História") pode ter contribuído para que o desenvolvimento científico-tecnológico tivesse ocorrido longe dos processos de trabalho. 
(...) a nova automação, de base microeletrônica, 'explode' a forma taylorista-fordista de produção, não genérica, mas localizada principalmente na grande indistria metal-mecánica (...). Essa nova automação significa uma abrupta, concentrada no tempo, recuperação do capital de seu brilhantismo quanto ao desenvolvimento das forças produtivas. (...) a 'explosão' da grande induistria taylor-fordista(...) significa o renascimento da análise marxista. Isto porque chegaremos, de forma genérica, homogênea a toda atividade industrial, a um elevadissimo grau de cientificização dos processos produtivos. A produção será, então, em todas as esferas da induistria, uma 'aplicação tecnológica da ciência', exatamente como afirmara Marx. Isto implica na volta triunfal da questão crucial para Marx da contradição entre forças produtivas e relações de produção, posta pelo desenvolvimento do modo de produção capitalista. $(\text { MORAES NETO, 2000, p. } 11)^{8}$

Este processo significa, de forma inequívoca, uma superação radical da "angústia smithiana", permitindo que se instaure em definitivo aquilo que Marx coloca com clareza nos Grundrisse, quando afirma que

o trabalho da produção material só pode adquirir o caráter livre e
emancipado se seu conteúdo se tornar diretamente social (obs: quando se
superar a forma social fundada na produçáa mercantil) e se se revestir
de um caráter científico (...), se deixar de ser o esforço do homem, sim-
ples força de trabalho natural no estado bruto tendo sofrido um deter-
minado treinamento, para se tornar a atividade do sujeito que regula
todas as forças da natureza no seio do processo de produção. (MARX,
1978, p. 119-120).

Chegamos, a partir do final do século 20, a um mundo inteiramente "grundrissizado", ou seja, plenamente ajustado à natureza explicitada por Marx nos Grundrisse para o processo de trabalho capitalista (MORAES NETO, 2005), permitindo finalmente que se efetive aquilo que Simone Weill (1983) - também por culpa do taylorismo-fordismo - considerava uma impossibilidade material, qual seja, um processo produtivo altamente eficiente comandado por um pequeno contingente de trabalhadores altamente envolvidos com seu trabalho, envolvimento esse inteiramente determinado pelo conteúdo pleno de sentido das atividades de trabalho. São essas as forças produtivas que, desenvolvidas pelo capitalismo, permitem à sociedade a propositura e a eventual conquista histórica de uma superação efetiva desse regime.

8 Sobre os desdobramentos desse processo recente de desenvolvimento científico-tecnológico, especialmente da radicalização da automação dos processos produtivos pela microeletrônica (e a consequente superação do fordismo), ver Fausto (1989), Moraes Neto $(2005 ; 2006)$ e Prado (2005). 
Fica claro, então, que a História pôs fim à impregnação do projeto socialista da mediocridade imanente ao taylorismo-fordismo, coisa que marcou de forma perversa a experiência socialista do século 20. De agora em diante, só tem sentido histórico dotar o projeto socialista de extrema ambição, posto que inteiramente impregnado da ideia fundamental da superação radical do trabalho alienado.

\section{REFERENCIAS}

BABBAGE, C. On the economy of machinery and manufactures. New York: Augustus M. Kelley Publishers, 1971.

BAILES, K.E. Alexei Gastev and the Soviet controversy over taylorism, 1918-24, Soviet Studies, v. 29, n. 3, 1977.

BEDEIAN, A .G.; PHILLIPS, C.R. Scientific management and stakhanovism in the Soviet Union: A Historical Perspective. International Journal of Social Economics, v. 17, 1990.

DEVINATZ, V.G. Lenin as scientific manager under monopoly capitalism, state capitalism, and socialism: A Response to Scoville. Industrial Relations, v. 42, n. 3, 2003.

FAUSTO, Ruy. A "pós-grande indústria" nos Grundrisse (e para além deles). Lua Nova, n. 19, 1989.

FINZI, R. Lênin, Taylor, Stakhanov: o debate sobre a eficiência econômica após outubro. In: HOBSBAWN, E. (Org.). História do marxismo. Rio de Janeiro: Paz e Terra, 1986.

GRAMSCI, A . Obras escolbidas . São Paulo: Martins Fontes, 1978.

LÊNIN, V.I. Primeira versão do artigo "As tarefas imediatas do poder soviético". In: BERTELLI, A .R. (Org.). Lênin: Estado, ditadura do proletariado e poder soviético. Belo Horizonte: Oficina de Livros, 1988a.

As tarefas imediatas do poder soviético. In: BERTELLI, A. R. (Org.). Lênin: Estado, ditadura do proletariado e poder soviético. Belo Horizonte: Oficina de Livros, 1988b.

LINHART, R. Lenine, os camponeses e Taylor. Lisboa: Iniciativas Editoriais, 1977.

MARCUSE, H. Razãa e revolução. Rio de Janeiro: Editora Saga, 1969.

MARX, K. El Capital. México: Fondo de Cultura Económica, 1973. . Manuscritos: economía e filosofía. Madrid: Alianza Editorial, 1974. - Miséria da filosofia. Porto: Publicações Escorpião, 1976. . Elementos fundamentales para la crítica de la Economia Política - Grundrisse. México: Siglo Veintiuno Editores, 1978. 
; ENGELS, F. A ideologia alemã. São Paulo: Editora Hucitec, 1991.

MORAES NETO, B. R. Marx, Taylor, Ford: as forças produtivas em discussão. São Paulo: Brasiliense, 1989.

. Fordismo e ohnoísmo: trabalho e tecnologia na produção em massa. Estudos Econômicos, v. 28, n. 2, 1998.

- Marx e o processo de trabalho no final do século. Pesquisa \& Debate , PUCSP, v. 11, n. 2, 2000.

. O percurso teórico da «abolição do trabalho» (ou da superação da «angústia smithiana) em Marx: avanços e recuo. Revista da Sociedade Brasileira de Economia Política, n. 14, 2004.

- Observações sobre os Grundrisse e a história dos processos de trabalho. Revista da Sociedade Brasileira de Economia Politica, n. 16, 2005.

- Pós-fordismo e trabalho em Antonio Negri: um comentário. Revista da Sociedade Brasileira de Economia Politica, n. 18, jun. 2006

PALMA, A . Le macchine e l'industria da Smith a Marx. Torino: Einaudi, 1971.

PRADO, Eleutério. Desmedida do valor: crítica da pós-grande indústria. São Paulo, Xamã, 2005.

ROSDOLSKY, R. Genesis y estructura de El Capital de Marx. México: Siglo Veitiuno Editores, 1985.

SCOVILLE, J. G. The Taylorization of Vladimir Ilish Lenin. Industrial Relations, v. 40, n. $4,2001$.

SMITH, A. Riqueza das nações. São Paulo: Abril Cultural, 1983.

SOCHOR, Z.A. Soviet Taylorism Revisited. Soviet Studies, v. 33, n. 2, 1981.

TRAUB, R. Lenin and Taylor: the fate of "scientific management" in the (early) Soviet Union. Telos, v. 37, 1978.

WEILL, S. A racionalização. In: BOSI, E. (Org.). A condição operária e outros estudos sobre a opressão. Rio de Janeiro: Paz e Terra, 1983.

WEISS, D. Marx versus Smith on the division of labor. Monthly Review, v.28, n.3, 1976.

WOOD, Stephen. O modelo japonês em debate: pós-fordismo ou japonização do fordismo. Revista Brasileira de Ciências Sociais, v. 17, n. 6, out. 1991.

. The japanization of fordism. Economic and Industrial Democracy, v. 14, 1993.

WREN, D. A.; BEDEIAN, A .G. The taylorization of Lenin: rethoric or reality? International Journal of Social Economics, v. 31, n. 3, 2004. 